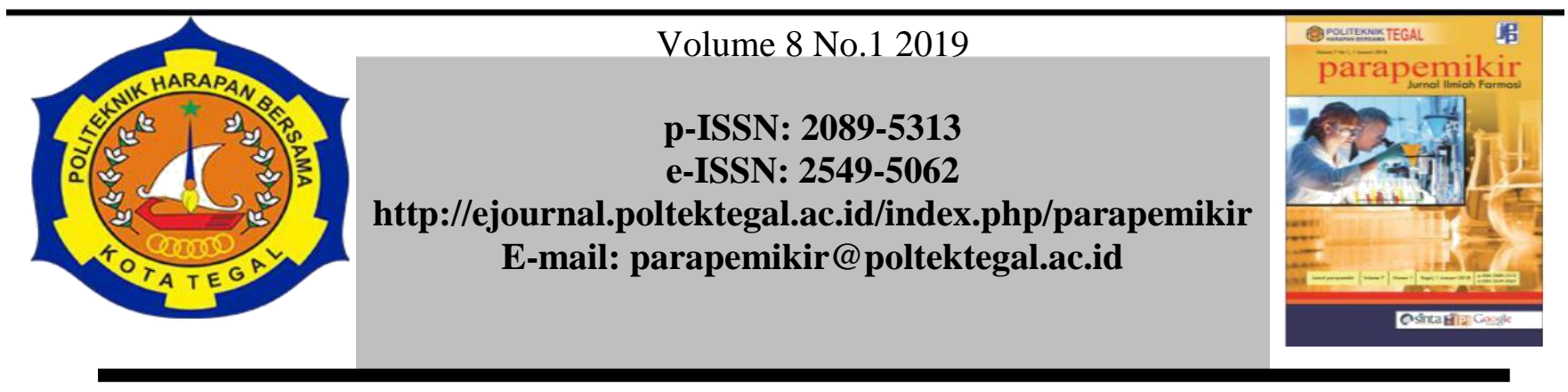

\title{
PEWARNA ALAMI EKSTRAK MASERASI BUNGA ROSELLA (Hibiscus sabdariffa
} L.)

\author{
Heru Nurcahyo*1, Kusnadi ${ }^{2}$ \\ 12 Prodi DIII Farmasi, Politeknik Harapan Bersama Tegal, Indonesia \\ Email : herunurcahyo7770@gmail.com,2kusnadi.adi87@gmail.com
}

\begin{tabular}{|c|c|}
\hline Article Info & Abstrak \\
\hline Article history: & \multirow{10}{*}{$\begin{array}{l}\text { Rosela mengandung senyawa antosianin yang dapat digunakan sebagai zat warna } \\
\text { merah alami. Bunga ini dikenal juga memiliki banyak khasiat (manfaat fungsional) } \\
\text { bagi kesehatan. Selain sebagai pewarna, rosella (Hibiscus sabdariffa L.) dapat } \\
\text { dimanfaatkan sebagai pengawet, karena mengandung antioksidan dan antibakteri. } \\
\text { Penelitian ini merupakan penlitian ekperimen laboratorium, yang dilaksanakan dengan } \\
\text { metode ekstraksi maserasi dengan memberikan intervensi pada temperatur dan pH zat } \\
\text { pembawa, dengan menggunakan metode ekstraksi secara maserasi, dan ekstrak yang } \\
\text { dihasilkan selanjutnya diisolasi antosianinnya dan dilakukan pengujian secara } \\
\text { organoletis, pH dan absorsi warnanya dilakukan dengan pengujian dengan } \\
\text { spektrofotometri UV-Vis. Hasil dari penelitian ini didapatkan nilai absorbansi dengan } \\
\text { panjang gelombang serapan maksimum untuk sampel warna merah alami rosela adalah } \\
510 \text { nm. Nilai terbaik tipe B dengan intervensi pada pH asam dengan kandungan asam } \\
\text { sitrat } 1 \% \text { dengan penekanan pada suhu kamar atau 250C dengan nilai absorbansi } \\
1,544 \text {. }\end{array}$} \\
\hline $\begin{array}{l}\text { Received Desmber } \\
2018\end{array}$ & \\
\hline Received in & \\
\hline revised form & \\
\hline Desember 2018 & \\
\hline Accepted Januari & \\
\hline 2019 & \\
\hline Available online & \\
\hline January 2019 & \\
\hline $\begin{array}{l}\text { Kata kunci: Rosela, } \\
\text { Antosianin, } \\
\text { Maserasi }\end{array}$ & \\
\hline \multirow[b]{2}{*}{\begin{tabular}{|l|} 
\\
\\
\\
Keywords: \\
Keywords: \\
Rosela, Anthocyanin, \\
Maserasi \\
\end{tabular}} & abstract \\
\hline & $\begin{array}{l}\text { Rosella contains anthocyanin compounds that can be used as natural red dyes. This } \\
\text { flower is also known to have many benefits (functional benefits) for health. Aside from } \\
\text { being a dye, rosella (Hibiscus sabdariffa L.) can be used as a preservative, because it } \\
\text { contains antioxidants and antibacterial. This research is a laboratory experiment study, } \\
\text { which was carried out by maceration extraction method by giving an intervention at the } \\
\text { temperature and pH of the carrier, using maceration extraction method, and the } \\
\text { resulting extract was then isolated by anthocyanin and organoletically tested, pH and } \\
\text { color absorption carried out by testing with UV-Vis spectrophotometry. The results of } \\
\text { this study obtained absorbance values with the maximum absorption wavelength for } \\
\text { the roselle natural red color sample was } 510 \mathrm{~nm} \text {. The best value of type B with } \\
\text { intervention at acid pH with } 1 \% \text { citric acid content with emphasis at room temperature } \\
\text { or } 250 \mathrm{C} \text { with an absorbance value of } 1.544\end{array}$ \\
\hline
\end{tabular}

Alamat korespondensi:

Prodi DIII Farmasi Politeknik Harapan Bersama Tegal

Gedung A Lt.3. Kampus 1

Jl. Mataram No. 09 Kota Tegal, Kodepos 52122

Telp. (0283) 352000 


\section{Pendahuluan}

Pewarna merupakan peranan penting dalam proses pengemasan beberapa produk makanan, miuman ringan, dan pakaian. Zat warna pada makanan maupun minuman dibagi menjadi tiga golongan yaitu zat warna sintetik, zat warna alami, dan zat warna identik [1]. Zat warna sintetik umumnya lebih cerah pewarnaannya, lebih stabil dalam berbagai kondisi, aplikasinya lebih luas, mudah penggunaanya, konsentrasi pigmen kuat, keseragaman warna lebih baik, tahan lama, lebih stabil pada saat proses pemasakan, dan lebih bervariasi. Sedangkan zat warna alami memiliki sifat kurang cerah, lebih sulit penggunaannya, kurang stabilsaat pemasakan, dan kurang bervariasi. Penggunaan zat warna sintesis sering menimbulkan penyakit dan masalah kesehatan seperti kanker, stroke, penyakit jantung, kerusakan ginjal dan hati [2], [3].

Dengan terbatasnya penggunaan jumlah zat warna alami dalam pengembangan dibidang industri di bidang kosmetik, farmasi, sandang, dan pangan menyebabkan terjidinya peningkatan penggunaan zat warna sintesis sehingga secara perlahan-lahan pemakaian zat warna alami mulai digantikan menggunakan zat pewarna sintesis [4]. Penggunaan pewarna sintesis cenderung bersifat toksik dan dapat meyebabkan kencemaran pada lingkungan karena merupakan bahan kimia yang berbahaya, bersifat karsinogenik, dan beracun [5].

Bahan kimia organik dari limbah industri tekstil yang mengandung pada zat warna sintesis akan bercampur dengan material koloid yang dapat meningkatkan pencemaran pada air. Air yang ditimbulkan dari pencemaran zat warna sintesis menyebabkan air menjadi berbau dan warnanya menjadi keruh [6]. Pewarna alami lebih aman digunakan pada produk farmasi, obat-obatan, kosmetik dan industri pangan karena tidak bersifat toksik, dapat diperbaruhi dan ramah lingkungan [7]. Salah satu bahan zat pewarna alami yang ramah lingkungan adalah bunga rosela.

Rosela (Hibiscus sabdariffa Linn.) dapat menjadi sumber pewarna alami merah karena dalam bunga ini terkandung antosianin [8]. Disamping menghasilkan pigmen antosianin, bunga ini dikenal juga memiliki banyak khasiat (manfaat fungsional) bagi kesehatan (Hasibuan ,dkk) Selain sebagai pewarna, rosella (Hibiscus sabdariffa L.) merupakan salah satu tanaman yang dapat dimanfaatkan sebagai pengawet, karena mengandung antioksidan dan antibakteri oleh Mardiani dan Kristiani dalam [9]

Masih sedikitnya penelitian yang mengeksplorasi tentang pewarna alami dari bunga rosela ini yang menjadikan penulis tertarik untuk meneliti lebih lanjut sehingga dapat dimanfaatkan sebagai pewarna yang dapat digunakan sekaligus sebagai anti bakteri, antioksidan, dan pengawet dalam bidang farmasi, kosmetika dan industri tekstil

II. Metodologi Penelitian

Penelitian ini merupakan penlitian ekperimen laboratorium, yang dilaksanakan dengan metode ekstraksi maserasi dengan memberikan intervensi pada temperatur dan $\mathrm{pH}$ zat pembawa.

Alat Penelitian. Alat-alat yang digunakan dalam penelitian ini adalah, seperangkat alat gelas, pisau atau alat pemotong, blender, timbangan analitik, kertas saring, sentrifuge, shaker, oven, almari es,waterbath, Spektrofotometer UV-Vis Varian Cary 50, dan Color reader Minolta CR 10, pH meter.

Bahan Penelitian. Bunga rosela, aquadest, asam sitrat, $\mathrm{HCl}, \mathrm{KCl}$, Na-Sitrat, Na-Asetat anhidrat, Na2HPO4.2H2O dan Asam Sitrat.

Pelaksanaan Penelitian. (1) menyiapkan sampel bunga rosela dengan sampel bunga rosela yang berasal dari kota tegal; (2) Sortasi basah dengan menghilangkan kotoran-kotoran yang melekat pada simplisia. (3) Pencucian dilakukan untuk menghilangkan tanah dan pengotor lainnya yang melekat pada bahan simplisia. Pencucian dilakukan dengan air bersih yang mengalir; (4) sortasi kering bunga rosela yang sudah bersih selanjutnya dikeringkan dengan matahari langsung sampai kering; (5) melakukan penyerbukan bunga rosela yang sudah kering selanjutnya dilakukan penyerbukan untuk mendapatkan ukuran 30 mesh; (6) maserasi serbuk bunga rosela selanjunya disiapkan untuk maserasi dengan perbandingan 1 : 7,5.

Tahap analisis dan pengambilan kesimpulan, dengan menguji kandungan antosianin dengan absorbansi warna yang dihasilkan dan menganalisis data untuk menarik kesimpulan

\section{HASIL DAN PEMBAHASAN}

Penelitian ini menggunapan sampel bunga rosela yang diekstraski dengna metode maserasi dan diuji kadar antosianinnya sebagai pewarna merah dengan intervensi pada suhu dan keadaan asam dalam melaksanakan ekstraksinya.

Esktrak bunga rosela di peroleh ekstrak dengan menggunakan metode maserasi, Langkah pertama yang di lakukan adalah menimbang serbuk Sampel. Sempel yang telah di timbang kemudian di maserasi selama 5 hari dengan menggunakan pelarut etanol $70 \%$ dan kondisi $\mathrm{pH}$ asam dengan menambahkan asam asetat $1 \%$ dan $2 \%$ dengan suhu 50C, 250C dan 400C. Di gunakan pelarut etanol $70 \%$ karena etanol tersebut lebih selektif, kapang dan kuman sulit tumbuh, absorbansinya baik, tidak menyebabkan pembengkakan pada membran sel dan memperbaiki stabilitas bahan obat terlarut, sifatnya yang mampu menghambat kerja 
enzim dan sangat efektif dalam menghasilkan jumlah ekstrak yang optimal.

Pada proses maserasi setiap hari perlu di lakukannya dengan pengadukan untuk memudahkan proses sirkulasi, Hal ini di maksudkan agar keseimbangan konsentrasi bahan efektif lebih cepat di dalam cairan. Setelah 5 hari kemudian di saring dengan kain flanel, Langkah berikutnya yaitu penguapan dengan menggunakan maserasi yang bertujuan untuk memisahkan kadar etanol yang masih terkandung dalam cairan sehingga di dapatkan ekstrak yang kental.

Ekstrak yang dihasilkan harus terbebas dari pelarut yang bertujuan agar ekstrak yang dihasilkan murni. Untuk memastikan ekstrak sudah terbebas dari pelarut maka dilakukan uji bebas alkohol

Tabel 1. Hasil uji bebas alkohol.

\section{Uji Pustaka Hasil Ket}

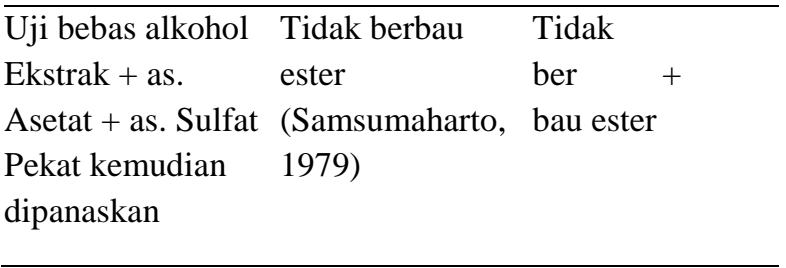

Keterangan :

(+) : Sesuai dengan pustaka

(-) : Tidak sesuai dengan pustaka

Dari hasil di atas dapat diketahui hasil uji bebas alkohol yang didapatkan memberikan hasil positif hal ini sudah sesuai dengan pustaka Sasongko (2010) yaitu tidak berbau ester. Hasil di atas dapat di simpulkan bahwa ekstrak daun kemangi sudah terbebas dari alkohol [10].

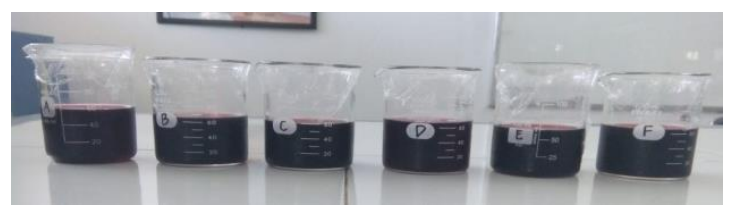

Gambar 1. Hasil isolasi antosianin

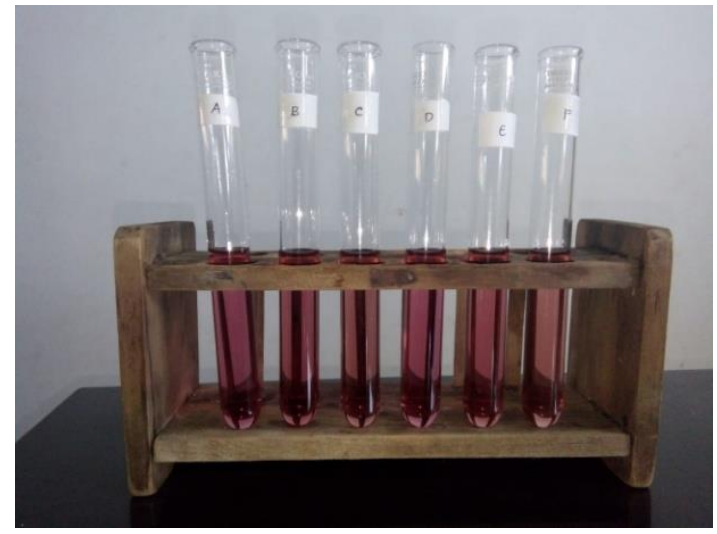

Gambar 2. Sampel uji absorbansi
Penetapan absorbansi antosianin dilakukan dengan spektrofotometer UV-Vis. Spektrofotometer digunakan untuk penetapan kadar karena mudah dikerjakan, waktu pengerjaan singkat dan diperoleh hasil yang valid. Setelah dilakukan pembuatan larutan blanko kemudian penentuan panjang gelombang maksimum. Panjang gelombang yang dipakai adalah 470, 480, 485, 490, 495, 500, 505, 510, 515, 520, 525, 530, 540, 545, 550, 555, 560, 565 dan $570 \mathrm{~nm}$ dengan pengujian 6 sampel uji dan tiga kali replikasi. Penentuan panjang gelombang maksimum bertujuan untuk mengetahui ketika absorpsi mencapai maksimum sehingga meningkatkan proses absorpsi larutan terhadap sinar. Nilai tertinggi menentukan capaian absorpsi warna paling maksimal sehingga penggunaan spektrofotometer perlu memperhatikan langkahlangkah yang sudah ditentukan.

Beberapa hal yang perlu diperhatikan dalam penggunaan spektrofotometer yakni pembentukan molekul yang dapat menyerap sinar UV-Vis yang dapat ditunjukan dengan pembentukan dan perubahan warna pada sampel yang diuji. Pengukuran absorbansi perlu memperhatikan waktu operasional yang stabil untuk mengukur hubungan panjang gelombang dengan absorbansi larutan. Pemilihan panjang gelombang yang diperoleh digunakan untuk analisis kuantitatif dengan mempunyai absorbansi maksimal [11].

Hasil penentuan panjang gelombang maksimum terbaik pada $510 \mathrm{~nm}$ dengan hasil sebagai berikut :

Tabel 2. Hasil Nilai Absorbansi antosianin

\begin{tabular}{lcccccc}
\hline Replikasi & $\mathrm{A}$ & $\mathrm{B}$ & $\mathrm{C}$ & $\mathrm{D}$ & $\mathrm{E}$ & $\mathrm{F}$ \\
& $\mathrm{pH}$ & $\mathrm{pH}$ & $\mathrm{pH}$ & $\mathrm{pH}$ & $\mathrm{pH}$ & $\mathrm{pH}$ \\
& asam & asam & asam & asam & asam & asam \\
& $1 \%$ & $1 \%$ & $1 \%$ & $2 \%$ & $2 \%$ & $2 \%$ \\
& suhu & suhu & suhu & suhu & suhu & suhu \\
& $5^{\circ} \mathrm{C}$ & $25^{\circ} \mathrm{C}$ & $40^{\circ} \mathrm{C}$ & $5^{\circ} \mathrm{C}$ & $25^{\circ} \mathrm{C}$ & $40^{\circ} \mathrm{C}$ \\
\hline 1 & 1,364 & 1,543 & 1,386 & 1,327 & 1,334 & 1,144 \\
2 & 1,366 & 1,543 & 1,388 & 1,327 & 1,334 & 1,144 \\
3 & 1,366 & 1,545 & 1,390 & 1,328 & 1,335 & 1,146 \\
\hline Rata2 & 1,365 & 1,544 & 1,388 & 1,327 & 1,334 & 1,145
\end{tabular}

Dari tabel diatas dapat diketahui bahwa serapan maksimum yang diperoleh sampel dengan warna merah alami rosela adalah $510 \mathrm{~nm}$. Panjang gelombang serapanmaksimum ini dapat dijadikan standar yang menjadi acuan konsentrasi pewarna roselayang dibuat. Serapan yang sama padapanjang gelombang yang sama menunjukkan konsentrasi yang sama dari molekul zatwarna yang dibuat. Panjang gelombang yang telah ditentukan digunakan untuk menghitung konsentrasi zat warna alami rosela dilakukan pada dalam tahap optimasi ini sesuai kadar warna yang dikehendaki, hal ini sesuai dengan hukum Lambert - Beer yaitu absorbansi sebanding dengan tebal medium dan konsentrasi. 


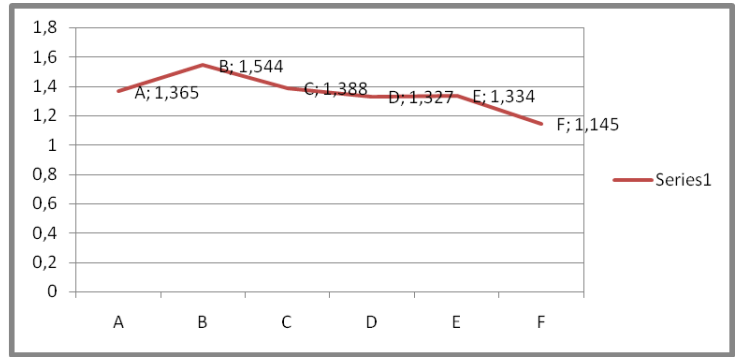

Gambar 3. Nilai absorbansi antosianin Dari data tersebut dapat diperoleh nilai terbaik adalah tipe $\mathrm{B}$ dengan intervensi pada $\mathrm{pH}$ asam dengan kandungan asam sitrat $1 \%$ dengan penekanan pada suhu kamar, hal tersebut sesuai dengan penelitian hayati (2012) Kestabilan warna senyawa antosianin dipengaruhi oleh $\mathrm{pH}$ atau tingkat keasaman, dan akan lebih stabil apabila dalan suasana asam atau $\mathrm{pH}$ yang rendah[12].

\section{KESIMPULAN}

Panjang gelombang serapan maksimum untuk sampel warna merah alami rosela adalah $510 \mathrm{~nm}$. Nilai terbaik adalah tipe B dengan intervensi pada $\mathrm{pH}$ asam dengan kandungan asam sitrat $1 \%$ dengan penekanan pada suhu kamar dengan nilai absorbansi 1,544 .

\section{REFERENSI}

[1] Bahri, S., Jalaluddin, Rosnita. 2017. Pembuatan Zat Warna Alami Dari Kulit Batang Jamblang (Syzygium Cumini) Sebagai Bahan Dasar Pewarna Tekstil, Jurnal Teknologi Kimia Unimal, 6(1), 10-19.

[2] Pujilestari, T. 2015. Sumber Dan Pemanfaatan Zat Warna Alam Untuk Keperluan Industri, Jurnal Dinamika Kerajinan dan Batik, Vol. 32, No. 2, 93106.

[3] Suarsa, I.W.,Suarya, P., dan Kurniawati, I. 2011. Optimasi Jenis Pelarut dalam Ekstraksi Zat Warna Alam Dari Batang Pisang Kepok (Musa paradiasiaca L. Cv kepok ) dan Batang Pisang Susu ( Musa paradiasiaca L. cv susu). Journal of Chemistry, 5(1): 72-80.

[4] Handarini, 2014, Potensi EkstrakBunga Rosella (Hibiscus Sabdariffa L.)Sebagai Pengawet Alami Yang Diaplikasikan Pada Daging Ayam Segar Pengganti Formalin.Jurnal Agroknow, Vol. 2. No.1. Halaman 1-70, ISSN :2302-2612, Pebruari 2014, diakses 19 Maret 2018
[5] Widjajanti, E., Regina T.P., dan Utomo, M. P. 2011.Pola Adsorpsi Zeolit Terhadap Pewarna Azo Metil Merah dan Metil Jingga.Prosiding Seminar Nasional Penelitian, Pendidikan dan Penerapan MIPA.hal K115-K122, Fakultas MIPA, Universitas Negeri Yogyakarta.

[6] Kant, R. 2012. Textile Dyeing Industry an Environmental Hazard, Open Access journal Natural Science, 4(1), Aticle ID :17027, 5 pages, DOI: 10.4236/ns.2012 .41004

[7] Yernisa, Gumbira-Sa'id, E. dan Syamsu, K.2013. Aplikasi Pewarna Bubuk Alami dari Ekstrak Biji Pinang (Areca catechu L.) pada Pewarnaan Sabun Transparan. Jurnal Teknologi Industri Pertanian, 23(3): 190-198.

[8] Handarini, K, 2014, Potensi Ekstrak Bunga Rosella (Hibiscus sabdariffa L.) Sebagai Pewarna Dan Pengawet Alami Pada Jelly Jajanan Anak, Jurnal Teknik Industri HEURISTIC Vol 11 No 2, Universitas Dr. Soetomo Surabaya, us sabdariffa L.), diakses pada 17 Maret 2018.

[9] Hasibuan, S., Mardiah, Saptuti. Aplikasi Pewarna Alami Antosianin Dari Kelopak Rosela Pada Produk Yoghurt Dalam Rangka Penganekaragaman Produk Pangan Fungsional. Fakultas Agribisnis dan Teknologi Pangan, Universitas Djuanda diakses 19 Maret 2018.

[10] Silalahi RJ. 2010. Penetapan kadar ketoprofen dalam sediaan tablet spektrofotometri ultraviolet [Skripsi]. Medan (ID): Universitas Sumatera Utara.

[11] Sasongko, DP, Tresna, WP, 2010, Identifikasi Unsur dan Kadar Logam Berat pada Limbah Pewarna Batik dengan Metode Analisis Pengaktifan Neutron, Pusat Penelitian Lingkungan Hidup Lemlit Universitas Diponegoro, Semarang, Pusat Penelitian Fisika - LIPI Kawasan Puspiptek Tangerang Selatan, Indonesia, Jurnal Ilmu Pengetahuan dan Teknologi TELAAH vol. 27, diakses 19 Maret 2018

[12] Handarini, 2014, Potensi EkstrakBunga Rosella (Hibiscus Sabdariffa L.)Sebagai Pengawet Alami Yang Diaplikasikan Pada Daging Ayam Segar Pengganti Formalin. Jurnal Agroknow, Vol. 2. No.1. Halaman 1-70, ISSN :2302-2612 